\title{
Letters
}

Website: bmj.com

Email: letters@bmj.com

\section{Redefining leadership}

\section{Successful leadership requires range of styles}

EDITOR-Treasure's views and comments after the NHS Confederation's leadership conference make interesting reading. ${ }^{1}$ The leadership style of consultants covers a broad spectrum that could be described as ranging from "huggy touchy feely" all the way up to "Attila the Hun meets Genghis Khan." A similar spectrum exists in managers. The British government's own Cabinet Office expert report on public service leadership indicates that successful leaders need to adopt a range of styles depending on the situation. ${ }^{2}$ That may include having to resort at times to coercive, browbeating styles.

Many consultants would perhaps choose to operate in the lower or middle range of the style spectrum. At times when managers do not listen to consultants' reasonable concerns about the delivery of safe, effective, high quality services there may be no option but reluctantly to wheel out Attila and Genghis to protect both patients and consultants.

Treasure is very fortunate to be in a specialty that is comparatively rich in resources and having its concerns addressed by major

\section{Advice to authors \\ We prefer to receive all responses electronically, sent directly to our website. Processing your letter will be delayed unless it arrives in an electronic form. \\ We are now posting all direct submissions to our website within 24 hours of receipt and our intention is to post all other electronic submissions there as well. All responses will be eligible for publication in the paper journal. \\ Responses should be under 400 words and relate to articles published in the preceding month. They should include $\leqslant 5$ references, in the Vancouver style, including one to the BMJ article to which they relate. We welcome illustrations. \\ Please supply each author's current appointment and full address, and a phone or fax number or email address for the corresponding author. We ask authors to declare any competing interest. Please send a stamped addressed envelope if you would like to know whether your letter has been accepted or rejected. \\ Letters will be edited and may be shortened. \\ bmj.com \\ letters@bmj.com}

new investments. Many consultants do not have that luxury and consider that what may be in the patients' best interests may conflict with the managers' financial best interests for their organisation. The priority and responsibility for both consultants and managers must be to place safety and quality issues for the public first and health service finance issues second. Judge the consultants' and managers' use of influence and abilities in an organisation by those criteria not jus by financial considerations. From Treasure's editorial it seems that the NHS Confederation's preferred style of leadership from consultants when working in partnership with senior managers would be for consultants conveniently to roll over and play dead. Appropriate, challenging questions and behaviours from consultants may help clarify muddled thinking and lead to a greater openness and transparency in the decision making processes of trusts and the Department of Health.

Nigel Dudley consultant in elderly medicine St James's University Hospital, Leeds LS9 7TF

1 Treasure T. Redefining leadership in health care. $B M$ J 2001;323:1263-4. (1 December.)

2 Performance and Innovation Unit. Strengthening leadership in the public sector. www.cabinet-office.gov.uk leadershipreport/defaulthtm (accessed 3 Decembe 2001)

\section{Hospital service needs doctors who are better educated and trained}

EDITOR-It is unfortunate for Treasure's case that changing hospitals from being places of pilgrimage to busy workplaces geared to delivering an evidence based and cost effective product has produced institutions many of which are dirty, unsafe, and inefficient, whose medical and nursing staff very often lack humanity in their dealings with patients, and whose standards are probably the lowest in western Europe.

Treasure's analogy of the English cricket 11 is not very apt. Both Ian Botham and his captain were and are cricket players, and both had the same objective: they wanted to defeat the Australians. The objectives of doctors often differ from those of managers Most doctors want to see patients, investigate their conditions, treat them, observe the results, and modify their practices according to those results. Most managers want or are obliged to abide by the instructions of the Department of Health and deliver the results required by it. We have seen this in the matter of inpatient waiting lists. These objectives may have little to do with the wellbeing of patients, but if managers do not comply, their careers will suffer.

Doctors have often behaved badly and inconsiderately. Encouraged by Margaret Thatcher and Kenneth Clarke, some joined the rush to private practice. Encouraged by lawyers, some relied in the courts on the Bolam principle to justify acts that were plainly negligent. Some betrayed patients, institutions, and colleagues in the search for ribands to stick in their coats. Some behaved badly to patients and concealed the results of bad practice. Some tried the patience of their colleagues sorely. Most of the time most doctors did their best for their patients within the constraints of available facilities; some even tried to get those facilities improved. A few succeeded. Mrs Thatcher and her successors changed all that, just as they changed the coal mining industry, the railways, the roads, the educational system, and the police service.

The collapsing hospital service needs doctors who are better educated and better trained rather than doctors of lower calibre who are wholly subservient to managerial direction. It needs managers who are better educated and more experienced in dealing with a diversity of people and who regard their task as one of leadership and of facilitation of clinical objectives rather than one of directing a compliant workforce to fulfil departmental aims.

G L W Bonney former orthopaedic surgeon to St Mary's Hospital, Paddington

6 Wooburn Grange, Grange Drive, Wooburn Green, Buckinghamshire HP10 OQU

1 Treasure T. Redefining leadership in health care. BMJ 2001;323:1263-4. (1 December.)

\section{Bullying in medicine}

\section{Those who can, do; those who can't, bully}

EDITOR-The experiences of the person who wrote an anonymous personal view about bullying in medicine is one I have heard related to my national workplace bullying advice line many times. ${ }^{1}$ Nursing and healthcare sector staff comprise about 12\% of more than 5000 cases that have been brought to my attention. Bullies are attracted to the caring professions by the opportunities to exercise power over vulnerable clients and over vulnerable employees, who will go to great lengths to protect their relationship with their vulnerable clients.

When a serial bully is present, competent staff (the majority) become disempow- 
ered and disenfranchised. No one dares speak up for fear of reprisals. If the writer of the personal view hadn't remained anonymous she would in effect be a whistleblower. Friends of the bully, powerful professionals, and their employers close ranks behind the alleged wrongdoer, and the whistleblower's career is effectively over.

The stereotype of a bully as a tough dynamic manager who gets the job done is slowly changing as we begin to recognise that the sole purpose of bullying is to hide inadequacy and incompetence. Employers are starting to understand the impact on budgets of high staff turnover, high sickness absence, impaired performance, lower productivity, poor team spirit, loss of trained staff to the profession, and increasing litigation by both injured patients and bullied employees.

The stereotype of a "victim" as a weak inadequate person who somehow deserves to be bullied is giving way to the realisation that bullies, who are driven by jealousy and envy, pick on the highest performing and most skilled staff, whose mere presence is sufficient to make the bully feel insecure. Threats (of exposure of inadequacy) must be ruthlessly controlled and subjugated. Those who can, do. Those who can't, bully.

Whether you've been a target or believe that it won't happen to you, almost everyone is at risk of becoming a target.

Tim Field founder, UK national workplace bullying advice line

PO Box 67, Didcot, Oxfordshire OX11 9YS timfield@successunlimited.co.uk

1 Bullying in medicine. BMJ 2001;323:1314. (1 December.)

\section{Both sides need help when bullying happens}

EDITOR-Bullying in the workplace is widespread and happens at all levels. ${ }^{1}$ I have experienced it myself in the NHS and have seen it happening to other people. Usually bullies are people in a position of power who bully people in training or lesser grades, but it also happens among peers, and I have seen people bullying their seniors.

Often bullies seek out easy targets: people with a passive nature who do not have much self confidence. Bullies can be openly aggressive and easy to recognise. But you should also beware of those who are indirectly aggressive, who pretend to be nice while stabbing you in the back.

Keeping a record of incidents, talking to others, and enlisting the help of witnesses are all important. There is relevant legislation, but work tribunals are not for everyone: they are daunting and stressful, and the outcome is uncertain unless good evidence can be produced. Perhaps even more important is that victims of bullying should learn to stand up for themselves, to see the incident, difficult and damaging as it is, as a growth opportunity in terms of personal development. I found that I could not change the other person but could change myself in a positive way, and now I am much more aware of the issues involved.

It is not only the victim of bullying who needs help. Unrelenting perfectionism and intimidation do not always result in career progress and promotion (though they often do, unfortunately) but may result in the person being demoted or losing their job. The situation can be particularly difficult for women bullies. Traditionally, women have been encouraged to adopt more aggressive and dominating behaviour to be able to compete in the male dominated workplace. Now, tough career women are being sent to remedial programmes to learn how to get in touch with their own vulnerability and be intuitive, nurturing, and compassionate.

Denying what is at the core of human existence does not make for happy living, and bullies do this at their peril. It is time for society to realise that being a caring individual is not a weakness but an asset, and essential for those responsible for managing others.

Kristin Becker consultant in clinical genetics North West London Hospitals NHS Trust, Harrow HA1 3UJ

k.becker@ic.ac.uk

1 Bullying in medicine. BMJ 2001;323:1314. (1 December.)

We must all learn from our unacceptable behaviour

EDITOR-In my 15 years as a general practitioner I have watched people in the NHS being horrible to each other. It is often the system that causes this behaviour. Most anger and criticism such as that described in the anonymous personal view is caused by anxiety and unhappiness in the bully. ${ }^{1}$

Unfortunately, many senior doctors are unaware that they have a problem. Only psychopaths are horrible and enjoy it. Most people are rude and horrible because they feel anxious, stressed, and put upon, and these emotions drive chronic bullying and rudeness. Elevated rank leads to years of this behaviour being unchallenged, which removes any chance of insight developing.

All of us in the NHS should have constant insight into how our frail emotions can influence our behaviour towards colleagues. Simple psychological models such as transference and projection explain most bad behaviour. It is a tragedy for healthcare workers that they can serve the public tirelessly and with kindness, only to then project their frustrations on to each other, undoing any good they have done with their patients by damaging colleagues.

Forgiveness and an open culture of discussion of stress is the way forward. I am no saint and have been rude and angry on many occasions. I hope that I learn every time I behave badly and reduce the frequency of those incidents.

Graeme M Mackenzie general practitioner Maryport, Cumbria CA15 8EL g.mackenzie@eidosnet.co.uk

1 Bullying in medicine. BMJ 2001;323:1314. (1 December.)
Summary of responses

bmj.com

We received 27 other responses to this personal view, all sympathetic to the widespread problem of bullying at work, 24 of which were published on bmj.com. Twelve of the respondents were senior doctors.

Only two respondents admitted to having been bullied. One had worked in the civil service and thought that "the history of the civil service as with the NHS is plagued by authoritarian rule.... There can be no team working in an environment where people are so busy concentrating on protecting the 'self' and completing the 'task' that they have no time to be part of the bigger picture." The other, in medical research, said, "When I finally complained and after having a breakdown, the trust responded by trying to have me dismissed."

Peter Bruggen, a retired consultant psychiatrist from London, suggested what the anonymous bullied doctor could do to make life more bearable using various techniques from psychotherapy. However, Graham Spiller, a pathologist in Canada, asked: "Why should Anonymous have to relinquish her career for a year? I suggest that the consultant surgeon could benefit from psychotherapy," adding "I suspect that [nasty senior doctors] have personality problems."

Peter Devitt, a consultant surgeon in Australia, sought an explanation for the case by describing the stresses and strains of consultants. "Being able to handle those situations is part of the challenge of being a consultant. It would appear that the consultant in question is unable to cope with those challenges."

Helen Morant, also from Australia, pondered on the effects of working in the NHS. "Is it possible that the victim of this bullying was less able to cope with harsh criticism because she was physically exhausted from working 90 hour weeks, mentally exausted from studying for exams on top of a more than full time job, and emotionally exhausted from telling several patients that week that they had diseases that would kill them?

"Is it possible that the bully had been 'toughened' by forcing her way to the top of a male dominated profession, constantly having to prove herself as a woman, and now realising pressures of constant managerial change, budget management, and underfunding as well as clinical commitments?"

The imbalance of power was blamed by I Agell, a specialist registrar in psychiatry in Huddersfield: "If a bullied person was capable of ending the incident they would do so."

Bullying is ubiquitous, certainly the type of bullying described in this personal view is not unique to the United Kingdom, confirmed Russell Lutchman, specialist registrar in forensic psychiatry at Broadmoor Hospital.

"Bullying is not a part of the medical training, but there will always be bullies. Bullying is part of the human condition," argued Neville Goodman, consultant anaesthetist in Bristol. 
So how can we stop bullying in medicine? John Boulton, a professor of medical practice in Australia, highlighted the importance of communication skills: "Although medical education has espoused the importance of teaching doctor-patient communication, it has lagged behind in doctor-nurse, doctor-doctor ... and doctor[other staff] communication skills." Medical and nursing students should be taught how to manage the rigours of interprofessional communication.

Jeremy Bolton, associate dean of the Kent, Surrey and Sussex Deanery, reported that the deanery requires all trusts to have an anti-bullying policy in place as part of the educational contract with the deanery. Perhaps all deaneries should do this.

Liz Crossan freelance technical editor, BMJ

1 Electronic responses. Bullying in medicine. bmj.com 2001 (www.bmj.com/cgi/eletters/323/7324/1314; accessed 19 March 2002).

\section{Violence in the workplace}

\section{Delirium should be considered}

EDITOR-The account of an assault on a nurse in the course of her work is distressing, and familiar to NHS staff. ${ }^{1}$ The clinical picture is of an agitated patient trying to leave the ward at night, within a day of admission with diabetic ketoacidosis. He was deemed unfit to be discharged, to the extent that the police were called to ensure his return to medical care. There may have been several causes for the violent outburst, for which the patient may rightly be held culpable. I was concerned, however, that all three commentaries failed to raise the possibility of delirium being relevant to the outburst. ${ }^{2}$

I encourage staff to press criminal charges when they are assaulted at work, as they would when out on the street or in their homes. But appropriate medical advice also needs to be available to police and staff if a patient is not legally responsible for his or her actions due to an acute confusional state secondary to his or her physical condition.

Explanations to staff members, with adequate training, robust protocols, and support proactively provided within the trust, may help to ameliorate the additional sense of distress engendered by a perceived failure of the legal system to prosecute in such cases.

Siobhan MacHale consultant liaison psychiatrist Department of Psychological Medicine, Royal Infirmary of Edinburgh, Edinburgh EH3 9YW ravelrig@fsmail.net

1 Violence in the workplace [with commentaries by $\mathrm{P}$ Gough, RM Goss, and S Jordan]. BMJ 2001;323:1362-4 (8 December.)

2 Meagher D. Delirium: optimising management. BMJ 2001;322:144-9.

\section{Mentally ill patients are responsible for} their actions

EDITOR-Goss writes in his commentary that a substantial majority of the violence against NHS staff is caused by "mental patients not responsible for their actions." He admits that this is slim comfort for the victims. It might be, if it was true. Most mentally ill patients are responsible for their actions (violent or not) most of the time.

Repeating the myth does not do any favours for staff, patients, or society at large. It encourages the minimisation of violent incidents in mental health settings, which leads to under-reporting by staff. It teaches the patients that their violent behaviour will be tolerated, and they escape the usual sanctions of the criminal justice system.

If the recommendations of the "zero tolerance campaign" are followed, patients accused of assaults on staff will face prison sentences. ${ }^{2}$ The issue of mental illness affecting criminal responsibility would be considered then if pertinent during the court process. This avoids exculpating mentally ill patients because of a paternalistic belief that they lack responsibility.

Goss later states that the man who assaulted the nurse should have been considered for a custodial sentence, presumably because he had a physical illness and was therefore more responsible for his attack than a generic "mental patient." Prejudging these patients by the above attitude would be unfair to both.

L M Tuddenham senior house officer in psychiatry Falkirk and District Royal Infirmary, Falkirk FK1 5QE

ltuddenham@doctors.org.uk

1 Violence in the workplace [with commentaries by $\mathrm{P}$ Gough, RM Goss, and S Jordan]. BMJ 2001;323:1362-4 (8 December.)

2 Department of Health. Zero tolerance zone: we don't have to take this. London: Stationery Office, 1999

\section{Zero tolerance is not helpful in mental health}

EDITOR-In his commentary Goss states that "a substantial majority" of violent acts in healthcare settings are committed by mentally ill patients not responsible for their actions. ${ }^{1}$ The first part of this statement may be true, but the assumption that "mental patients" by definition are not responsible is certainly false.

The vast majority of psychiatric patients are responsible for their behaviour, both morally and legally, as shown by the vanishingly small numbers of individuals ever found not guilty by reason of insanity in court. Even actively psychotic patients usually remain legally responsible for their actions and able to exercise choices in their behaviour.

Holding them responsible for their behaviour is another matter. It is now government policy that those who assault staff should receive custodial sentences. It also remains government policy that mentally disordered individuals who commit offences should not receive custodial sentences but should be admitted to hospital. ${ }^{2}$ The contradiction is manifest, except to those who make such policies.

The "zero tolerance campaign" proposes excluding patients from treatment in extreme circumstances, yet a central function of community mental health services is to maintain contact with patients, particularly those who display antisocial behaviour. Society increasingly demands that mental health services protect the public, sometimes at the expense of patients' autonomy. The care programme approach, assertive outreach programmes, and other initiatives are explicitly designed to impose care on individuals who may be unwilling to receive it. Not surprisingly, some become hostile or aggressive in response, and frontline staff pay the price.

A minority of patients are treated unwillingly under the Mental Health Act. Telling detained patients who do not wish to be in hospital that they will be excluded from treatment if their behaviour is extreme enough seems likely to increase, not reduce, violence to staff. If mental health is where the majority of the problems arise, as Goss claims, then responses are needed that are appropriate and workable.

No one will condone violence towards NHS staff, although most of us will have witnessed or been the victim of such violence. But zero tolerance is no way forward, certainly in mental health. NHS staff deserve genuine protection, not soundbite policies that sound tough but are incompatible with the realities of practice.

Chris Jones consultant forensic psychiatrist

Norvic Clinic, Norwich NR7 0HT

christopher.jones@norfmhc-tr.anglox.nhs.uk

1 Violence in the workplace [with commentaries by $\mathrm{P}$ Gough, RM Goss, and S Jordan]. BMJ 2001;323:1362-4 (8 December)

2 Home Office. Provision for mentally disordered offenders. London: HO, 1990. (HO66/90.)

\section{Language of self harm is somatic and needs to be learnt}

EDITOR-In a recent personal view a doctor is exasperated at having to deal with the "bloody overdoses" as a house officer and then becomes one 25 years later. ${ }^{1}$ A patient who had had depression for 20 years and then harmed herself responded with a poem to staff in accident and emergency departments who think that victims of self harm are a waste of time and resources. ${ }^{2}$ I was moved by this poem. Self harm is a somatic language. It is a language which uses the body instead of words and feelings. This poem will speak to both victims of self harm and professionals who care for them precisely because it translates the language of self harm.

Staff who care for victims of self harm often do not have the time or skills required to translate this language. Instead they are often overwhelmed with concerns about risk management. Thus the concern about whether a patient intended to die and whether he or she is still at risk over-rides the key question: "what is this person trying to communicate to me or to others through the language of self harm?"

The poem illustrates how self harm can be an attempt to deal with chaotic feelings in a person's mind. These feelings will 
often include anger and hatred, which the self harmer may be trying to communicate to one or more others who have let them down, abandoned them, or abused them. The self harmer may be unable to express these feelings in words or may feel that verbal expression is too dangerous. The language of the body is used as an alternative means of communication.

Other chaotic feelings underlying self harm may include intense emotional pain and hurt. This can feel so unbearable and uncontrollable that the individual uses self injury to convert emotional pain into physical pain, which at least can be attended to and controlled through physical interventions. An emotional wound cannot be sutured. The language of overdosing oneself is less about converting inner emotional pain into bodily pain and more about obliterating the emotional pain altogether, at least for a brief time.

Many acts of self harm are attachment seeking. This aspect of the language of self harm is often pejoratively referred to as attention seeking or manipulative. I prefer to refer to attachment seeking behaviour as something that all human beings engage in at different times in their life. Every person from cradle to grave has a basic longing to be attached to one or more others. This longing is lifelong, although it may become buried if the person's attachment needs are repeatedly betrayed. From this perspective, self harm may function to avert abandonment or keep others at arm's length.

Why is it that healthcare staff so often respond to self harm in a resentful and rejecting manner? I think that this is partly because they feel communicated to in a language that they do not understand. The staff's emotional response is often a clue to the translation of the language of self harm. Thus, self harm that expresses an anger or hatred that cannot be expressed in words may elicit an angry or hateful emotional response in the caring professional. Understanding this can enable all staff who work with such patients to manage their own emotional responses without taking it out on their patient.

What can be done?

Firstly, training programmes for staff who are likely to work with victims of self harm need to teach about the language of self harm.

Secondly, such staff need to have opportunities to reflect on their emotional responses to self harm. These opportunities may take the form of staff support groups, sensitive supervision, or input from trained relational psychotherapists.

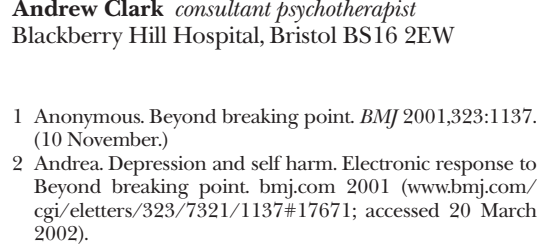

2 Andrea. Depression and self harm. Electronic response to Beyond breaking point bmj.com 2001 (wwwbmj.com cgi/eletters/323/7321/1137\#17671; accessed 20 March 2002).

\section{Statins as the new aspirin}

Conclusions from the heart protection study were premature

EDITOR-With reference to the news item by Kmietowicz, in their press release the directors of the heart protection study did not mention that their results were substantially worse than in the previous Scandinavian simvastatin survival study $(4 \mathrm{~S})$ (table). ${ }^{123}$

The way the results were presented exaggerates the benefit for the individual patient. The most interesting figure is survival because most myocardial infarctions heal with minimal cardiac dysfunction, if any. Tell a patient that his chance not to die in five years without statin treatment is $85.4 \%$ and that simvastatin treatment can increase this to $87.1 \%$. With these figures in hand I doubt that anyone should accept a treatment whose long term effects are unknown. For example, it was claimed that the study presented uniquely reliable evidence that simvastatin is not carcinogenic But the study went on for about five years only, just like other statin trials. It is not possible to say anything about the risk of cancer because it takes decades to disclose chemical carcinogenesis in human beings. Heavy smoking, for example, does not induce lung cancer in five years. All the statins and also the fibrates have proved carcinogenic in rodents, and it scares me that, if the new American guidelines for cholesterol treatment are followed strictly, half of mankind may take statins in a few years and for the rest of their lives. ${ }^{4}$

Low cholesterol concentrations have been related to depression, cognitive impairment, and suppression of the immune system. Does a reduction of $1.7 \%$ in mortality balance these risks? As in the previous trials, the effect of simvastatin was independent of the initial cholesterol concentration; patients with low concentrations benefited just as much (or just as little) as patients with high concentrations. The best results were seen in patients older than 75 years, an age group in which the lowest quartile of cholesterol concentration had the highest total and cardiovascular mortality.

That statin treatment works in patient and age groups in whom a high cholesterol concentration is not a risk factor for cardiovascular disease shows that the benefit is not the result of cholesterol lowering. High or low cholesterol concentrations are markers for other, more important disease factors; they are not causal factors themselves.

Uffe Ravnskov independent researcher Magle Stora Kyrkogata 9, S-22350 Lund, Sweden uffe.ravnskov@swipnet.se

Absolute risk reduction (\%) in two trials of simvastatin

\begin{tabular}{lcc} 
& Heart protection study ${ }^{\mathbf{1}}$ & $\begin{array}{c}\text { Scandinavian simvastatin survival study } \\
\mathbf{( 4 S}^{\mathbf{3}}\end{array}$ \\
\hline CHD mortality & 1.2 & 3.5 \\
\hline Total mortality & 1.7 & 3.3 \\
\hline All stroke & 1.5 & 3.5 \\
\hline Any major CHD & 3.1 & 6.7 \\
\hline
\end{tabular}

$\mathrm{CHD}=$ coronary heart disease
1 Medical Research Council/British Heart Foundation Heart Protection Study. Press release. Life-saver: World's for high-risk patients. Available at www.ctsu.ox.ac.uk/

2 Kmietowicz Z. Statins are the new aspirin, Oxford

3 Scandinavian Simvastatin Survival Study Group. Randomised trial of cholesterol lowering in 4444 patients with coronary heart disease: the Scandinavian simvastatin survival study (4S). Lancet 1994:344:1383-9.

4 Newman TB, Hulley SB. Carcinogenicity of lipid-lowering drugs. JAMA 1996;275:55-60.

5 Schatz IJ, Masaki K, Yano K, Chen R, Rodriguez BL, Curb JD. Cholesterol and all-cause mortality in elderly people from the Honolulu heart program: a cohort study. Lancet 2001;358:351-5.

\section{National Institute for Clinical Excellence} should assess statins

EDITOR-Although the heart protection study is good news, it is premature to say that statins are the new aspirin. ${ }^{1}$ An aspirin tablet a day costs just over $1 p$ whereas simvastatin costs $£ 1.06$ at the doses used, and it would cost the NHS almost $£ 400 \mathrm{~m}$ each year to treat 1 million people. Also, although the trial was large, it would only detect adverse reactions that occur more often than about one in 3000 patients and rare, serious reactions that may occur when a large population is exposed to the drug will have been undetectable. ${ }^{2}$

Cerivastatin was voluntarily withdrawn by Bayer in 2000 after reports of 31 deaths from rhabdomyolysis in the United States. This disorder has also occurred with other statins. It sounds as if the National Institute for Clinical Excellence needs to weigh up the risks, benefits, and costs of using statins.

Christopher Anton administrative coordinator West Midlands Centre for Adverse Drug Reaction Reporting, City Hospital NHS Trust, Birmingham B18 7QH

christopher.anton@cityhospbham.wmids.nhs.uk

1 Kmietowicz Z. Statins are the new aspirin, Oxford researchers say. BMJ 2001;323:1145. (17 November) 2 Eypasch E, Lefering R, Kum CK, Troidl H. Probability of adverse events that have not yet occurred: a statistical reminder. BMJ 1995;311:619-20.

\section{Case of cholestatic hepatitis with celecoxib did not fulfil international criteria}

EDITOR-O'Beirne and Cairns reported a case of cholestatic hepatitis in association with celecoxib. ${ }^{1}$ This case does not, however, fulfil the accepted international criteria for cholestatic hepatitis as it was not confirmed histologically. ${ }^{2}$ Biochemical criteria of cholestatic hepatitis require the presence of alkaline phosphatase activity over twice the upper normal limit or a ratio of alkaline phosphatase to alanine aminotransferase activity $>2$, or both. ${ }^{2}$ Neither was fulfilled, largest cholesterol-lowering trial reveals massive benefits hps/pr.shtml (accessed 19 March 2002). researchers say. BMJ 2001;323:1145. (17 November.) 


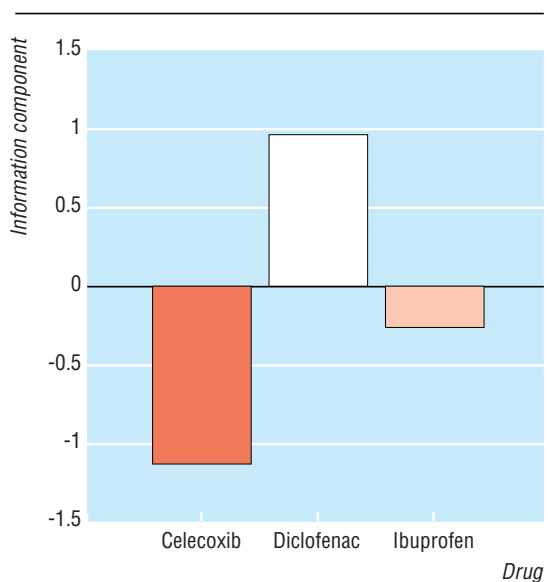

Information components for cholestatic hepatitis from WHO safety database

even when using aspartate aminotransferase as a surrogate of alanine aminotransferase, which was not provided. Moreover, the patient did not experience an actual positive rechallenge as, during the first exposure to the drug, she experienced only pruritus, which is not specific for hepatitis.

The incidence of cholestatic hepatitis in the general population is unknown. But the incidence of acute liver injury in the general population is 4-5 per 100000 person years. ${ }^{3}$ García-Rodriguez reviewed eight studies of drug induced acute liver injury and found that 50 of 102 cases $(49 \%)$ were cholestatic hepatitis. $^{4}$

Assuming that $49 \%$ of cases of acute liver injury in the general population are cholestatic hepatitis, its incidence can be estimated to be 2-2.5/100 000 person years. As of 30 June 2001, the worldwide exposure to celecoxib is estimated to be 10.6 million patient years (21.5 million patients with an average of six months' treatment). Therefore, the number of expected cases of cholestatic hepatitis should range between 208 and 260. As of 30 June 2001 we had received 14 cases of adverse events reported as cholestatic hepatitis in patients treated with celecoxib worldwide. The receipt of these is influenced by an unknown degree of under-reporting, inherent to the spontaneous reporting system. Regardless, the 14 reported cases fall within the limits of what could be expected, given the widespread use of celecoxib.

We conducted an analysis of the international drug monitoring database of the World Health Organization, which contains spontaneous reports from 57 countries. ${ }^{5}$ The figure shows that the information component (the measure of the association between adverse reaction and drug that is used by the WHO at the Uppsala Monitoring Centre to monitor safety signals) of cholestatic hepatitis $(-1.15)$ for celecoxib is not significantly different from background expectation or ibuprofen $(-0.30)$. The information component of cholestatic hepatitis for diclofenac (0.92) was significantly higher than background $(\mathrm{P}<0.05)$
Causality can rarely be ruled out or attributed with certainty on the basis of single case reports. We continue to monitor the safety profile of celecoxib and welcome the reports of possible safety signals. The current existing evidence does not, however, support a causal association between celecoxib and cholestatic hepatitis.

Felix M Arellano chief safety officer Sean Z Zhao director pharmacoepidemiology Matthew W Reynolds pharmacoepidemiologist Pharmacia Corporation, 100 Route 206 North, MS 135, Peapack, NJ 07977, USA

1 O'Beirne JP, Cairns SR. Cholestatic hepatitis in association with celecoxib. BMJ 2001;7:23. (7 July.)

2 Council for International Organizations of Medical Sciences (CIOMS). Reporting adverse drug reactions. Geneva: CIOMS, 1999.

3 Rodriguez LAG, Gutthann SP, Walker AM, Lueck L. The role of non-steroidal anti-inflammatory drugs in acute liver injury. BMJ 1992;305:865-8.

Rodriguez $\mathrm{AC}$, Ruigomez A, Jick $\mathrm{H}$. A review of . epidemiologic rescarch on dnug- Jick King the general practice research database in the United

Bate A, Lindquist M, Edwards IR, Olsson S, Orre R, Lansner A, et al. A bayesian neural network method for adverse drug reaction signal generation. Eur J Clin Pharmacol 1998;54:315-1.

\section{Mini-cholecystectomy is often used in gallbladder surgery}

EDITOR-We are surprised that in his review of the gall bladder as a cause of upper abdominal pain Johnson fails to mention small incision cholecystectomy (minicholecystectomy) as an alternative to the laparoscopic approach. ${ }^{1}$ This was being used before laparoscopic surgery was adopted, with excellent results-for example, $88 \%$ of patients were being operated on as day cases. It is unfair to compare laparoscopic surgery with the traditional (large incision) open operation, which is only occasionally done now.

Several randomised controlled trials comparing mini-cholecystectomy and laparoscopic cholecystectomy have shown virtually no difference between them, except that laparoscopic surgery is more expensive. If Johnson is unhappy with the findings of the Sheffield trial, we would draw his attention to a large Swedish trial with over 700 patients, conducted to the same single blinded design. ${ }^{2}$ The findings of this study closely paralleled our own.

Mini-cholecystectomy is an even better option for suspected common bile duct stones than the methods mentioned by Johnson: it is easy to explore the duct through this carefully placed small incision, and even to do a cholecystoduodenostomy if necessary.

\section{A G Johnson head of surgery}

A W Majeed senior lecturer

University of Sheffield, Division of Clinical Sciences, Section of Surgical and Anaesthetic Sciences, Academic Surgical Unit, Royal Hallamshire Hospital, Sheffield S10 2JF

\footnotetext{
1 Johnson $\mathrm{CD}$. $\mathrm{ABC}$ of the upper gastrointestinal tract Upper abdominal pain: Gall bladder. $B M$ 2001;323:1170-3. (17 November.)

2 Ros A, Gustafsson L, Krook H, Nordgren CE, Thorell A, Wallin G, et al Laparoscopic cholecystectomy versus minilaparotomy cholecystectomy: a prospective, randomized, ingle-blind chuly. Anu Sirg 2001,294:741-9.
}

\section{Several databases give free access now}

EDITOR-Delamothe mentions several initiatives to provide free access to biomedical literature. ${ }^{1}$ Medline is a medical database that may be enough for a general search and is accessible free via PubMed (http:// pubmed.gov). For a comprehensive search, however, it can be important to search other databases too. The choice depends on the subject area, how much time you have, and whether you can access databases that charge (the American and United Kingdom governments provide free access to some databases)

The Cochrane Database of Systematic Reviews is a key source for the effectiveness of treatments. It is free to NHS staff via the knowledge section of NeLH (www. nelh.nhs.uk/), and the abstracts are free to everyone (www.update-software.com/ cochrane/). Related free databases include DARE (the database of abstracts of reviews of effectiveness), NHS EED (the NHS economic evaluation database), and HTA (health technology assessment) (all at http://agatha.york.ac.uk/welcome.htm); the Research Findings Register via NeLH; and TRIP, a database that searches over 55 sites of high quality medical information (www.tripdatabase.com/).

Other free databases include the Hazardous Substances Databank and Toxline for toxicology, via Toxnet (http://toxnet. nlm.nih.gov/). Zetoc is free at point of access to NHS staff in England via NeLH, and to higher education in the United Kingdom. At least $40 \%$ of the 19 million citations to journal articles and conference proceedings in zetoc are in health subjects, although there are no abstracts or indexing.

Important databases are supplied by hosts for a fee. DIALOG's website gives an indication of the huge range (http:// library.dialog.com/essentials.html). When searching on line for a fee, I use Medline and any of several databases (the following are just some examples):

- Embase for additional European and pharmacology journals, and for quicker indexing (it is included in the BMA's "Medline plus" service)

- PsychINFO for academic psychology

- AMED (allied and complementary medicine database) for palliative care, professions allied to medicine (members of the Chartered Society of Physiotherapy have free access), and complementary medicine

- DHSS-Data for health administration (in addition to the large amount free on the Department of Health website)

- CINAHL (the cumulative index to nursing and allied health database) or the British Nursing Index for nursing

- The science or social science citation indexes (also part of the "web of science") for citations.

Readers should check with their medical librarian if they are doing a comprehensive search, or haven't found what they need in Medline. He or she can suggest other 
relevant databases to access and can probably help to search more effectively. For example, PubMed has a lot of useful features that aren't obvious (more information at www.bl.uk/services/information/blmedline. html).

Fiona McLean health care information officer British Library, London NW1 2DB fiona.mclean@bl.uk

Competing interests: The British Library runs the STM online search service, provides Medline training, and produces AMED and zetoc.

1 Delamothe T. Navigating across medicine's electronic landscape, stopping at places with Pub or Central in their names. BMJ 2001;323:1120-2. (10 November)

\section{Medline and PubMed will be able to synthesise clinical data}

EDITOR-In their editorial Smith and Chalmers call for a new and most welcome initiative that would provide access to a synthesis of valid, relevant clinical information. ${ }^{1}$ Those of us responsible for the original Medline database wish success to any endeavour that hopes to transform health care (and that might bring honour to the Queen). Your readers might be interested to learn about some recent improvements of our own in this direction.

The US National Library of Medicine began to link sources on the internet from the inception of free PubMed access to Medline in 1997. (It was vice president $\mathrm{Al}$ Gore, not the then first lady Hillary Clinton, who announced free access to Medline via PubMed at a ceremony in the US Congress.) The LinkOut feature of PubMed is designed to provide users with a wide variety of relevant web accessible resources, including full text articles, biological databases, consumer health information, research tools, and more. PubMed also links users to an extensive database, ClinicalTrials.gor, which provides patients, family members, and the general public with current information about clinical research studies. In 2002 PubMed citations will include links from the American College of Physicians Journal Club and other evidence based medicine journals to the original journal article being commented on.

Late in 2001 we complemented our "clinical queries" feature, which filters references using a method based largely on the work of Haynes et al, with a new filter called systematic reviews. ${ }^{2}$ This feature has much the result in mind as the proposal by Smith and Chalmers-the ability to retrieve systematic reviews and meta-analysis studies for a specific search topic. Since the systematic reviews filter is so new and as yet unpublicised, they were not mentioned in the editorial. The Cochrane Database of Systematic Reviews, which has been indexed in Medline since 2000, is among the evidence based resources. Moreover, Clinical Evidence has been approved for indexation in Medline, and its citations, with full text links, will begin to appear in PubMed early in 2002.

Sheldon Kotzin chief

Bibliographic Services Division, National Library of Medicine, Bethsda, MD 20850, USA

Kotzin@nlm.nih.gov

1 Smith R, Chalmers I. Britain's gift: a "Medline" of synthesised evidence. BMJ 2001;323:1437-8. (22-29 December)

2 Haynes, RB, Wilczynski N, McKibbon KA, Walker CJ, Sinclair K. Developing optimal search strategies for detecting clinically sound studies in Medline. J Am Med Inform Assoc 1994;1:447-58.

\section{Vitamin A programme in Assam probably caused hysteria}

EDITOR-Did the recent campaign to distribute vitamin A in Assam, India, cause an epidemic of illness or hysteria? The public health science underlying vitamin A prophylaxis and the reports that emerged after the same-day dosing of some 2.5 million preschool children point to hysteria.

Firstly, did vitamin A kill a child the day after dosing, and up to 13 children the next week, as claimed (overdosage by a new, larger delivery cup is being cited as the cause)?' Almost certainly not. Even twice the prophylactic dose of $200000 \mathrm{IU}$, had it been given (it is not clear that this routinely happened), is the recommended treatment for xerophthalmia. ${ }^{2}$

In blaming deaths on vitamin A critics have chosen to ignore the current mortality among 1-4 year old children in India of about 7 deaths per 1000 children per year. Thus 17500 of these children would be expected to die over the coming year without getting vitamin $\mathrm{A}$, including 48 the next day, or over 325 within a week-far more than the 14 deaths claimed to have been caused by the campaign. The inference to be drawn from this calculation suggests that vitamin A saved the lives of children, not took them.

Was there an unexpected epidemic of illness? Not unexpected. High potency vitamin A causes transient nausea, vomiting, and headache in 3-9\% of children. ${ }^{4}$ Ailments resolve within 48 hours, as reportedly occurred in Assam. In young infants a similar percentage may develop an isolated, bulging fontanelle that subsides within 72 hours. ${ }^{5}$ These consequences pose the "risk" of this programme.

At a rate of 5\%, 125000 dosed children would have been expected to develop side effects-far in excess of the 15000 cases reported by the media. Still, this number presenting to health clinics on the same day in one state results in a concentration of risk that could readily invite public scrutiny and a media outcry. Educating functionaries of the programme and the public that transient ailments may arise from receipt of vitamin A may prevent such difficulties in the future.

A nutritious diet is undeniably preferred for preventing vitamin A deficiency, but until such a goal is achieved periodic delivery of vitamin A can prevent xerophthalmia, reduce severity of infection, and improve children's survival. ${ }^{2}$ This is the "benefit" side of the equation, which seems to have been ignored in the hysteria surrounding the Assam programme.

Keith P West Jr professor

kwest@jhsph.edu

Alfred Sommer professor

Bloomberg School of Public Health, Johns Hopkins University, Baltimore, MD, 21205, USA

1 Mudur G. BMJ.com news roundup. Deaths trigger fresh controversy over vitamin A programme in India. $B M J$ 2001;323:1206. (24 November.)

2 Sommer A, West KP Jr. Vitamin A deficiency: health, survival and vision. Oxford: Oxford University Press, 1996.

3 Unicef. The state of the world's children 2001-early childhood. New York City: Unicef, 2000.

4 Florentino R, Tanchoco CC, Ramos AC, Mendoza TS, Natividad EP, Tangco JB et al Tolerance of preschoolers to two dose strengths of vitamin A preparation Nutr 1990:52:694-700.

5 Agoestina T, Humphrey JH, Taylor GA, Usman A Surdja D, Hidayat S, et al. Safety of one 52-mumol $(50,000 \mathrm{IU})$ oral dose of vitamin A administered to neonates. Bull WHO 1994;72:859-68.

\section{Full time forensic pathology service}

\section{Practical alternative to forensic pathology service exists}

EDITOR-Milroy and Hunt draw attention to the adverse publicity surrounding several wide ranging issues involving the medical profession. ${ }^{1}$ We agree that the investigation of deaths has deficiencies and the decision to undertake necropsy should be assisted by experienced and appropriately trained practitioners who could, in addition, be responsible for collecting, correlating, and analysing data so that unusual events or trends and practices are rapidly identified and investigated.

There are major practical problems in establishing a full time forensic pathology service to undertake this role. Forensic pathology services in England and Wales are depleted, overstretched, and in an apparent state of decline. There are, for example, now no university based forensic pathology services in London, a major capital city. A notable number of pathologists now work independently of any academic body, involved in neither research nor training the next generation of forensic pathologists. Given the current depleted numbers, barely able to cover current workload and subject to an apparent lack of future succession planning, it is difficult to see where the forensic pathologists required by Milroy and Hunt in their regional strategy proposal will be found.

There is, however, a body of medical practitioners with experience in law and forensic medicine which has considerable practical experience in assessing and examining medical evidence and skills in presenting this evidence in court. These are forensic physicians or police surgeons. They are used to working independently in the criminal justice and civil legal systems, often 
dealing with highly sensitive and complex issues. It seems quite feasible therefore that the establishment of a full time service for screening medical cause of death could be based on existing forensic physicians and that these medical screeners-as the report of the Home Office review of death certification suggests ${ }^{2}$ - could logically be linked to, and incorporated within, an enhanced coroner service supported by suitably trained and skilled coroners' officers.

Jason Payne-James editor, Journal of Clinical Forensic Medicine

jasonpaynejames@cs.com

Ian Wall barrister at law

Forensic Healthcare Services, London E9 7EH

Peter Dean Her Majesty's coroner

Coroner's Office, Rochford Police Station,

Rochford, Essex SS4 1BL

1 Milroy C, Hunt W. Full time forensic pathology service needs to be established. BMJ 2001;323:1183-4. (17 November.)

2 Home Office. Report of the Home Office review of death certification. London: Home Office, 2001.

\section{Role of clinical necropsy in medical} practice needs to be strengthened

EDITOR-I agree with Milroy and Hunt in their proposal. ${ }^{1}$ The introduction of overseeing medical examiners, a reduction in the remit of the coroners, the effective elimination of cremation forms, and a better organised and nationally uniform forensic pathology service are worthy aims. ${ }^{2}$

But it is not clear whether such a service will serve clinical governance better than existing arrangements. Since a large proportion of deaths subject to necropsy by the coroner are deaths that occurred in hospital, often after complex medical and surgical interventions, the new systems must incorporate measures that ensure the optimum use of information from autopsies. This requires the raising of standards of necropsy performance, interpretation, and reporting, and the reflexion of the ensuing data into hospitals' audit processes.

Several factors mean that clinicians and hospitals are not getting the best information out of what necropsies are done, and, ultimately, the public is not being best served. ${ }^{3}$ Too many necropsies are performed at public mortuaries, away from the hospital where the death occurred and where the clinicians could view and discuss the process. Too many are done hurriedly with inadequate correlation of the relevant clinical circumstances. There are limitations placed on tissue retention for diagnosis under current coroner's rules (and interpreted ever more strictly since the organ retention problems became public). A strict limitation is still applied on who may receive necropsy reports in some coronial jurisdictions. There is a disinclination to use pathologists with special expertise to examine appropriate deaths-apart from Home Office registered pathologists for suspicious deaths and paediatric pathologists for perinatal and child deaths.
When the Home Office's review into the coroner's system reports its recommendations on the necropsy aspects, let us hope that it strengthens the role of the clinical necropsy in medical practice in the 21st century, and does not relegate it further into the role of merely excluding unnatural death. Implicit is a reconciliation of demands and expectations in necropsy practice through two unrelated government departments: the Home Office in charge of coroners and the Department of Health in charge of medical practice.

Sebastian Lucas professor of histopathology Department of Histopathology, Guy's, King's, and St Thomas' School of Medicine, St Thomas' Hospital, London SE11 6SP sebastian.lucas@kcl.ac.uk

1 Milroy C, Hunt W. Full time forensic pathology service needs to be established. BMJ 2001:323:1183-4. (17 needs to

2 Lucas SB, Bobrow L, Collins C. Time to abolish cremation

fees. BMJ 1984;289:435, 764 .
Lucas SB. The coroner's autopsy and clinical governance. CPD Cellular Pathol 2001;3:117-9.
Cucas SB. The coron's autopsy

\section{Same shortcomings of NHS have existed for years}

EDITOR-Smith et al's editorial comments on the current problems of the NHS. ${ }^{1}$ They mention several shortcomings that I and many colleagues have wearied of highlighting to governments: decades of massive underinvestment and serious shortages of acute and intensive care beds and of general practitioners, consultants, nurses, and other healthcare professionals.

In a debate on the NHS in the House of Lords in November 2001 many excellent speeches followed my opening remarks, but, as is usual in such debates in the Lords, the views were ignored by the media (including the $B M /$ ). I made several recommendations to the government that I regarded as crucially important in the present, sad state of the NHS-sad despite the dedication and skill, often deployed under intolerable conditions, of most healthcare professionals. I had six principal recommendations:

- Increase acute and intensive care beds urgently and reopen closed community hospitals, which accept patients after early discharge from acute services, thus reducing bed blocking

- Expedite increases in general practitioners, consultants, and nurses (who will require increased remuneration to attract them to the service)

- Expand rapidly all public-private collaboration so as to use to better advantage spare capacity in the private sector

- Restore and extend tax relief on private medical insurance, withdrawn because of outdated ideological concepts

- Implement rapidly the Savill report of the Academy of Medical Sciences and the Follett report and reduce sharply the clinical pressures on academics to correct the parlous state of clinical academic medicine
- Lastly, as I recommended to the Merrison Royal Commission on the NHS more than 30 years ago, consider urgently introducing an index linked, income related health tax, probably as a supplement to national insurance. I shall again be told, of course, that the Treasury won't stand for hypothecated taxation; will any government have the courage to confront that body in order to introduce such a much needed reform?

Walton of Detchant

13 Norham Gardens, Oxford OX2 6PS

1 Smith J, Walshe K, Hunter DJ. The "redisorganisation" of the NHS. BMJ 2001;323:1262-4. (1 December.)

\section{Therapeutics needs to be better taught}

Editor-Eaton's News piece on the Audit Commission's report A Spoomful of Sugar draws attention to the increasing mortality attributable to adverse drug reactions and prescribing errors. ${ }^{12}$ I would like to make one point. Newly qualified doctors (preregistration house officers and senior house officers) are responsible for most of the drug prescribing for hospital inpatients. It is therefore surprising that the report does not consider that the training of medical undergraduates is an issue that should be addressed if we wish to reduce the mortality due to prescribing errors and the adverse effects of drugs.

At the time of qualification, and when preregistration house officers start their new jobs, doctors must be able to take a drug history, know how to treat the common conditions with drugs, prescribe correctly and safely, and be well informed about the potential for drugs to cause harm. It follows that medical schools should have an effective department of therapeutics and that the students' knowledge of therapeutics should be rigorously assessed in their final examinations.

The number of departments of therapeutics is decreasing, the assessment of therapeutics in many medical schools is inadequate, and mortality from the adverse effects of drugs is increasing. These factors might be related, and it is sad that the Audit Commission did not consider this.

Martin J Kendall professor of clinical pharmacology Clinical Investigation Unit, Queen Elizabeth Hospital, Birmingham B15 2TH

m.j.kendall@bham.ac.uk

1 Eaton L. Adverse reactions to drugs increase. $B M J$ 2002;324:8. (5 January.)

2 Audit Commission. A spoomful of sugar. Wetherby: Audit Commission Publications, 2001.

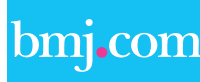

\section{Rapid responses}

Correspondence submitted electronically is available on our website 